\title{
Is Argument for Conservatives? or Where Do Sparkling New Ideas Come From?
}

\section{Sharon Bailin}

Abstract: Rorty claims argument is inherently conservative and philosophical progress comes from "sparkling new ideas," not argument. This assumes an untenable opposition between the generation and the evaluation of ideas, with argument relegated to evaluation. New ideas that contribute to progress arise from critical reflection on problems posed by the tradition, and constrained by the criteria governing evaluation. Thinking directed toward the criticism and evaluation of ideas or products is not algorithmic; it has a generative, creative component. An overall assessment in any complex circumstance requires constructing a new view from the questioning, weighing, rejecting, reconciling, and integrating of numerous divergent points of view. Thus, the process of argumentation can issue in new ideas.
Résumé: Rorty prétend que l'argumentation est fondamentalement en soi conservateur et que le progrès philosophique provient des "nouvelles idées étincelantes" et non pas de l'argument. Cela présume une opposition indéfendable entre la génération et l'évaluation des idées, reléguant l'argument à l'évaluation. Des idées nouvelles qui donnent au progrès proviennent de la réflexion critique sure des problèmes que la tradition posent, sous le contraint des critères qui régissent l'évaluation. La pensée visée sur la critique et l'évaluation des idées ou des produits n'est pas mécanique; elle possède un composant de génération, de création. Une évaluation globale dans n'importe quelles circonstances complexes demande un nouveau point de vue construit de l'intérrogation, du pesée, du refus, de la conciliation et de l'intégration des plusieurs points de vue divergents. Ainsi proviennent des idées nouvelles du processus de l'argumentation.

Keywords: argument, argumentation, philosophical progress, criticism and evaluation, new ideas, Rorty.

\section{Introduction}

In his review of the book, Rorty and His Critics (Brandom 2000), Simon Blackburn makes the following observation:

Rorty denies that philosophical progress comes about through argument. As he rightly reminds us, argument requires premises and conclusions that belong to the same conceptual family [or field]. Argument, it follows, is for conservatives. And real progress, by contrast, means 'offering us sparkling new ideas or utopian visions of glorious new institutions,' disabusing us of old routes of inference and feeling, enabling us to forget where we once were. It does not mean anything so flat as mere argument $(2001,39)$. 
The job of coming up with these sparkling new ideas, of proposing new vocabularies, of changing the world, falls to the "strong poet." The role to which those of us engaged in argumentation are relegated seems to be that of the accounting clerk, fitted with visor and sleeve protectors, scrutinizing the ledger book of ideas, making sure that the books balance and that no calculation errors have been made.

I would venture to say that many, perhaps most, of us working in the areas of argumentation theory, informal logic and critical thinking like to think of the practice to which we are committed as progressive, as contributing to social betterment and intellectual advance. We may prefer to imagine ourselves out toiling in those conceptual fields, boots immersed in the muddy waters, planting and grafting as well as pruning and weeding, and perhaps even harvesting a crop from time to time. I suspect that most of us, whatever our political stripe, would resist the idea that we are confined, by the very nature of our disciplinary practice, to simply uphold and perhaps rearrange the status quo, either intellectually or politically. But this is the picture that Rorty paints. In this paper I want to look at whether he is right. Can sparkling new ideas arise from argument?

\section{Rorty's View}

Let me begin by briefly rehearsing those aspects of Rorty's broader position that frame his views about argument. A central aspect is that it is anti-foundational. He denies the possibility of absolute, certain foundations for knowledge and instead claims that justification is to be sought within human practices. Such justification is, moreover, limited to particular practices, language games or vocabularies but makes no sense between vocabularies. Argument cannot, then, adjudicate between vocabularies. And even the standards and principles that guide evaluation have no normative force but are simply ways of describing the practice. To think otherwise is to commit the fallacy of "seeing axioms where there are only shared habits, or viewing statements which summarize such practices as if they reported constraints enforcing such practices" (Rorty 1991, 26).

Consistent with this position, Rorty maintains that the kind of philosophy that he is doing and advocating does not involve putting forth arguments. He denies that he is playing the game of rational discussion but claims, rather, to be engaged in a different practice which he describes thus:

It [the new method of philosophy] does not pretend to have a better candidate for doing the same old thing which we did when we spoke in the old way. Rather, it suggests that we might want to stop doing those things and do something else. But it does not argue for this suggestion on the basis of antecedent criteria common to the old and the new language game. For just insofar as the new language game really is new, there will be no such criteria (Rorty 1989,9).

He describes the practice in which he is engaged as 'redescribing', and states that the aim is to make such redescription attractive so that people will begin to adopt the new vocabulary. Moreover, it is this process of adopting new vocabularies on 
the basis of their aesthetic appeal and not that of rational choice of alternatives based on argument which effects changes in the culture.

\section{Intellectual Innovation}

I have described Rorty's view not primarily with the aim of engaging in Rortyan exegesis per se, but rather in order to highlight certain features of the position and bring out the more general picture of intellectual innovation on which his view of argument rests.

One central feature that marks innovation for Rorty is discontinuity. Innovative ideas exhibit a radical sort of novelty. They are not simply continuations and extensions of the previous vocabulary but are characterized by a complete break with what has come before. And because of this lack of continuity, new vocabularies are incommensurable with those they have superceded. This incommensurability means that the innovation cannot be evaluated in terms of the criteria that governed the previous vocabulary.

Another feature of the Rortyan view of innovation is that it draws a radical distinction between the generation and the evaluation or criticism of ideas. The activity of criticism (or argument) is seen as rule-bound and rigid, constrained by the logic of the particular framework or vocabulary. Innovative ideas are radically new in the sense that they break free of this logic. Thus they cannot arise in the context of the application of evaluative criteria of the previous framework - these criteria would keep one trapped within the old framework. New ideas cannot be a product of a logical process of incremental alteration of antecedent ideas and views. The generation of innovative ideas must be, in some sense, non-logical and unconstrained. Generation and criticism are seen, thus, as qualitatively different and even opposed sorts of activities.

Stated thus, it becomes clear that Rorty's is but one version of a view about creativity that appears, and has appeared historically, in many contexts and guises. Among its most prominent proponents were the Romantics. Reacting against the rationalism of the Enlightenment and the classical emphasis on tradition, the Romantic poets and theorists glorified the imagination and viewed the arts not as imitation but as bringing something new into the world. Coleridge, in particular, highlighted the role of the creative imagination in producing something new and unprecedented, thereby transforming the artist into a God-like creator (Taylor 1989). Such a feat could not be the result of traditional rules or patterns. It was thought to be, rather, the product of poetic inspiration, which differs from ordinary ideation in that it is sudden, effortless and unanticipated. Abrams $(1953,189)$ describes it thus: "The poem or passage springs to completion all at once, without the prior intention of the poet, and without that process of considering, rejecting, and selecting alternatives which ordinarily intervene between the intentions and the achievement" (in other words, without critical judgment). Poetic inspiration is the province of the creative genius. We can recognize the genius because there is "no 
mechanism in him or his work, nothing that can be analyzed and rationalized" (Barzun 2000,475). The genius creates "without precedent either in concrete example or in codified precepts and rules" (195). Originality is the hallmark of artistic creation for the Romantics and the genius is the originator par excellence. The Romantics believed that, in creating beauty, the artist also revealed truth; as a consequence they had great faith in the power of the creative genius to change the world. Poets, according to Shelley, are "the unacknowledged legislators of the world" (quoted in Barzun, 474). What we have, then, is a picture of a special sort of individual who, through an act of imagination, creates an original, artistic vision, a vision that is unanticipated, unprecedented and not the result of traditional rules or critical judgment, but a vision that can change the world. This is the Romantic creative genius-or Rorty's strong poet.

Although the Romantic view focused on the arts, the picture of innovation that it elaborated has been extended into other areas as well, including scientific discovery. An influential version is that of Thomas Kuhn (1962) in his distinction between normal science and revolutionary science. Normal science, the mainstay of scientific activity, takes place in the context of a fixed paradigm which guides research, specifying the problems to be undertaken and the procedures, rules and criteria to be used in investigating these problems. Normal scientific activity is uncritical of the assumptions of the paradigm. Revolutionary science, on the other hand, is characterized by a radical departure from the prevailing paradigm and the creation of a completely new one. This new paradigm is not a logical continuation of the previous one, but involves a new way of viewing phenomena and is, thus, incommensurable with the old paradigm. Since criteria of evaluation are applicable only within paradigms, there can be no paradigm-neutral criteria according to which to choose between paradigms. Thus the acceptance of a new paradigm is not made on the basis of rational evaluation but can only be a type of conversion or gestalt switch. The parallels between Kuhn's view of theory change in science and the view of innovation offered by Rorty are very strong.

Another aspect of the Romantic view of innovation applied to science can be seen in the theories of Paul Feyerabend (1975). Feyerabend denies that there are any rules of method that are consistent and invariable with respect to all scientific practice. This is not a descriptive claim about poor scientific practice, however. Rather, he is making the claim that there could not be such rules, that the adherence to any invariable rules of method would be detrimental to scientific progress because they would keep one locked into the presuppositions of an existing theory. The only way in which the hold of a prevailing theory can be broken is by the positing of an entirely new theory, unconnected with the old one. The only method he accepts for scientific discovery is 'anything goes.'

And even Karl Popper, although disagreeing with Feyerabend's claims regarding the impossibility of rules of method for the evaluation of theories, holds strongly to a discovery/justification distinction and relegates discovery to the realm of the irrational. 
[M] y view of the matter, for what it is worth, is that there is no such thing as a logical method of having new ideas, or a logical reconstruction of this process. My view may be expressed by saying that every discovery contains 'an irrational element', or 'a creative intuition,' in Bergson's sense (1959, 32).

Aspects of this Romantic view of creativity have also thoroughly permeated popular consciousness, but in a somewhat democratized form. There is common acceptance of the idea that innovations are radically new and that mode of thinking different from everyday logic is required to generate new ideas. One popular example is Edward de Bono's (1970) concept of lateral thinking. In contrast to vertical thinking, which is logical, evaluative and involves remaining rigidly within a framework, lateral thinking is strictly generative, producing new ideas without judging them, defying the logic of the framework, and making new connections between disparate elements.

One difference between the Romantic view of innovation and this contemporary popular version is that this special mode of creative thinking is no longer thought to be the exclusive purview of the genius. Rather, it can be learned and so is, in principle, open to everyone. Hence the plethora of creativity self-help books and do-it-yourself creativity videos with evocative titles such as $A$ Knock on the Side of the Head and $A$ Kick in the Seat of the Pants, that offer suggestions for 'breaking set' and 'thinking outside the box' (my favourite is the video guaranteeing to make you more creative in 30 days or your money back). Such materials warn of the dangers of too much logic; suggest techniques such as visualization, stimulating thinking with random information, and brainstorming (i.e., generating without judging); and offer advice such as: break the rules, unlearn what you know, follow your dreams, and consult a fool (von Oech 1986, 1993; Adams 1986).

One conclusion that can be drawn from this quick march through theories of creativity is that Rorty's view has a history and is linked to a tradition of thinking about issues regarding the nature and source of innovation and the role of logic and argument therein. It is not a new idea. The question still remains, is it sparkling?

\section{Critique}

I believe that there are serious problems with Rorty's view of innovation and of argument and that these significantly detract from the lustre of his idea.

\section{I Discontinuity}

First, the claim regarding the discontinuity between vocabularies/paradigms/frameworks is problematic both conceptually and empirically. On the conceptual front, the problem is that comprehension seems to presuppose continuity. If a new idea or practice emerged which were totally unconnected with any human traditions 
and practices, we would not be able to understand it. It is connections to what is familiar that render innovations comprehensible and give us grounds for seeing them as innovations as opposed to merely being strange. Innovations arise in the context of an enterprise that has a history and is part of a tradition, and the tradition has a direction, goals and meaning in light of which originality can be recognized.'

The discontinuity thesis also faces problems on the empirical front in that a close analysis of actual cases of innovation seems regularly to reveal continuities between new works and tive previous traditions. The arts represent the model of creation for the Romantics, and to some extent for Rorty, yet even here connections to the problems, methods and techniques of the tradition seem always to be in evidence. A radical innovation such as Picasso's cubism, for example, can be seen as an attempt to grapple with a specifically artistic problem-the simultaneous portrayal of multiple perspectives. Moreover the continuity with the work of earlier and contemporary artists such as Cézanne, Matisse, Derain and Delacroix, and the influences of Iberian sculpture and non-European art are very clear.

Such continuities are evident in science as well. Numerous historians and philosophers of science have pointed out the conceptual and methodological continuities between successive theories and have demonstrated that even scientific discoveries that may appear revolutionary have their roots in the problems and theories of previous paradigms. Hattiangadi (1980), for example, describes Newton's development of the law of gravitation in terms of entirely logical physical and mathematical arguments. Brown (1977) illustrates how Einstein's theoretical innovations arose from his arguments against existing theories and took as their point of departure some of the ideas of the rejected hypotheses. And Toulmin (1972) demonstrates that neither the changeover from Newtonian to Einsteinian physics nor the 'Copernican revolution' were characterized by the kind of complete rational discontinuity that Kuhn suggests. Rather, these changes were gradual and there is clear evidence that they were "argued every step of the way" (105). He points out, for example, that the testimony of the physicists who switched from a classical to a relativistic position shows no evidence of an intellectual conversion. Rather "they presented the arguments that sanctioned their change of theoretical standpoint" (104). Similarly, Kuhn's own historical account makes clear that the 'Copernican Revolution' took a century and a half to complete and was the outcome of rational discussion (105). Toulmin summarizes thus:

We must face the fact that paradigm-switches are never as complete as the fully-fledged definition implies; that rival paradigms never really amount to entire alternative world-views, and that intellectual discontinuities on the theoretical level of science conceal underlying continuities at a deeper, methodological level (105-106).

It may be that some changes in traditions appear so radical because we tend to view them from a distance. A closer analysis may be required to see the continuities. Indeed, this is the conclusion of Miller's (1984) historical study documenting 
the gradual development of the new quantum theories in the early twentieth century:

The notion of scientific revolutions describes only the gross structure of scientific change. In the fine structure, where change is gradual, resides the fascinating problem of the nature of creative scientific thinking (301).

The realm of social and philosophical innovation seems to be of particular interest to Rorty, but here too continuities to past thought are everywhere in evidence. The types of innovations that might be thought to manifest progress have built upon, as opposed to completely overturning, previous social and philosophical ideas (Bailin 1992c). The insights of critical theory, for example, can be traced back through Marx to Hegelian dialectic, and many feminist theories are rooted in previous Marxist and liberal philosophies. The critical theorist Henri Giroux (1991) acknowledges this continuity thus:

Modernism provides theoretical elements for analyzing both the limits of its own historical tradition and for developing a political standpoint in which the breadth and specificity of democratic struggles can be expanded through the modernist ideals of freedom, justice, and equality. (2-3)

Sandra Harding (1990) makes a similar point with respect to feminist theory:

However a specifically feminist alternative to Enlightenment projects may develop, it is not clear how it could completely take leave of Enlightenment assumptions and still remain feminist. The critics are right that feminism (also) stands on Enlightenment ground (99).

The discontinuity thesis is a crucial supporting plank in Rorty's view about the origins of innovation, but it cannot bear the weight of close scrutiny.

\subsection{Generation and Evaluation}

Let me turn, then, to the other main plank of his view, the opposition between the generation and the criticism of ideas. To recap, the principle idea is that the activity of criticism, which is the realm of argument, is confined within the bounds of particular frameworks (paradigms or vocabularies). It is not, however, possible between frameworks because all criteria of evaluation are framework-specific. For this reason, the generation of new ideas cannot be the product of an evaluative process. Rather, it is a creative process involving imagination, inspiration and arational leaps. Generation and criticism are distinct and mutually exclusive kinds of thinking.

There are problems here as well. I think that this opposition is lent plausibility by the discontinuity thesis. If innovation really were discontinuous with past frameworks, then it might appear that the kind of thinking applicable within the framework could not lead to the transcending of the framework. Conceptual change might seem to require explanation in terms of a special kind of thinking. Once it is recognized, however, that there are continuities between frameworks and that some of the criteria of evaluation will remain intact, then a motivating reason for positing such a dichotomy disappears. 


\section{Generation as Critical}

What of the claim that the generation of new ideas cannot be the product of an evaluative process, in other words that generation is uncritical? It is important to note that what is of interest here is originality, not mere novelty. The generation of novelty is easy. Any random word or bizarre act may be new. What is at issue are new ideas that are effective or valuable, that meet a need or solve a problem, that are significant in the context of a domain-new ideas that contribute to progress, new ideas that sparkle. And it seems clear that the generation of such ideas must involve critical judgment and evaluation. Critical judgment is required in the initial identification of some phenomena as in need of exploration or explanation. Recognizing the inadequacies in current approaches and deciding that a new approach is required are also aspects of generation that involve critical evaluation. And determining potentially fruitful directions for exploration or investigation and recognizing possible solutions or satisfactory outcomes are products of judgment as well. The generation of effective new ideas must be constrained by critical criteria. If it were not, the results would be chaos not creation. Not all assumptions, criteria and methods can be overturned. Some elements of the previous framework must remain, elements in the light of which the new idea takes on meaning and significance. ${ }^{2}$

Thus I would argue that the criteria of critical appraisal do not have to be discarded in order to transcend some of the assumptions of the current framework. Rather, one is led to question current assumptions in the light of one's reasoning about the problem or reflection on the situation. It would seem, then, that becoming entrenched in one way to view a problem is not a case of being trapped by the critical procedures of the tradition as Feyerabend, among others, would claim, but is, rather, a failure to be sufficiently critical.

The idea that the generation of new ideas is uncritical also rests on a particular view of the nature of the frameworks within which critical thinking operates. Frameworks seem to be conceived of as rigidly bounded and highly rule-governed, with all the information for making judgments contained within the framework. Yet there are only a very limited number of cases in which we operate within such clear-cut, clearly defined, and rigidly bounded frameworks (formal logic or the game of chess might be examples). In most instances of problemsolving and creation, however, frameworks overlap, shift and have indefinite boundaries. Moreover, relevant considerations may emanate from a variety of perspectives or frames of reference (Bailin 1992a).

Given the above, there is no need to posit non-rational, imaginative leaps to explain the generation of new ideas. Going beyond the information given is, rather, a feature of all our intelligent thought and behaviour and does not require special explanation. A number of psychologists have pointed out the incremental nature of thinking that leads to innovation and have demonstrated how ordinary processes such as noticing, recognizing, searching, remembering, and evaluating can, to- 
gether, contribute to creative results (Weisberg 1993; Perkins 1981). This is not to deny the reality of the feeling of insight we often experience when getting an idea or solving a problem. It is to deny only that such a feeling is an accurate indication that an a-rational leap has actually taken place.

In suggesting a role for critical judgment in innovation, it may appear that I am rejecting the well-known distinction in philosophy of science between discovery and justification and arguing for a logic of discovery. That is not entirely the case, however. The discovery/justification distinction is meant to suggest that considerations relating to discovery are irrelevant to the justificatory enterprise, and I am not disputing this. Whether the solution to a scientific problem were discovered in a laboratory or revealed by the Oracle of Delphi would have no bearing on its justification. What I am claiming is that criteria of justification play a role in discovery. I am disputing Popper's claim that discovery is irrational.

Given what we know about the world and about the practice of science, the Delphic Oracle theory of discovery is not a plausible one. Discoveries do not suddenly spring forth fully formed absent of context. Rather, scientific discoveries arise in the context of ongoing scientific investigation. A scientist is always in media res, working on particular problems within a rich problem context that includes previous theories, experimental results, techniques of analysis, and standards for judging the worth of scientific contributions (Schaffner 1980, 198). These are the source of both ideas and constraints. In the course of this activity, problems evolve and are refined and new problems emerge. As Nickles so aptly put it (pace Samuel Butler): "A theory is but a problem's way of generating new problems" (Nickels 1980, 53).

And the context is the source of constraints on the possibilities for solution. Nickels again:

[T] he constraints constitute a rich supply of premises and context-specific rules for reasoning toward a problem solution and permit us to explain the fact that scientists do reason to solutions (37).

These arguments suggest a process of discovery not as a single moment of inspiration, but rather as a gradual, ongoing process in which insight and justification are interwoven. Hattiangadi (1980) argues, in fact, that it is impossible to clearly distinguish pure contexts of discovery, since any idea that might be considered in the context of discovery with respect to one theory will itself be a part of the context of justification of a previous theory out of which it developed. Finocchiaro (1980) makes the same point with respect to Galileo's Dialogue Concerning the Two Chief World Systems:

[S]uppose that the whole Dialogue is categorized as an attempt to prove Copernicanism, and hence placed in the context of justification; in the course of such an attempted proof one may find himself formulating the principle of mechanical relativity, or of conservation of motion. Then the same book constitutes context of discovery from the point of view of those principles (94-95). 
I am not here arguing for a logic of discovery in the sense of an algorithm for making discoveries. I am, rather, arguing for the rationality of discovery. I would agree with Nickels $(1980,40)$ that "discovery normally is a reasoned, judgmental process (too rich to be informatively captured by a content-neutral logic)."

\section{Criticism as Generative}

We have seen the problems with the idea that the generation of novel ideas is noncritical. I believe that there are also problems with the complementary idea, namely that criticism lacks a generative component. This idea is based on the assumption that the activity of criticism is strictly analytic, selective and rule-determined. Given the necessary information from within the relevant framework and the appropriate reasoning techniques, the process of arriving at a judgment is largely algorithmic.

A closer examination of the process of criticism would suggest, however, that critical evaluation is not algorithmic but has a generative, imaginative component. ${ }^{3}$ The application of evaluative criteria is seldom automatic but involves the interpretation of the situation and imaginative judgment regarding their applicability and satisfaction. Overall assessment in any complex circumstance requires the consideration of alternatives and ultimately the construction of a position based on the weighing, reconciling and integrating of a variety of points of view.

Let us take, as an example, the species of argument criticism that is the domain of informal logic. Due to its ancestry in formal deductive logic, the domain of informal logic may appear a closed system involving algorithmic procedures for the correct assessment of arguments. This seems, in fact, to be the picture of argument that underlies Rorty's view. Such a model becomes inappropriate, however, when dealing with real arguments in natural language. In the latter case, argument criticism, although constrained by rules, is not determined by rules but is a constructive enterprise (Bailin 1990).

Criticism involves, first, the interpretation of arguments, but this is not a straightforward and simple process. We construct an interpretation guided by textual information but texts are always and necessarily incomplete, and at times several plausible inferences can be made depending on background knowledge and assumptions. This incompleteness also means that the receiver has a role to play in constructing meaning, leaving open the possibility of differing equally justified interpretations.

Supplying the missing premises and unstated assumptions of an argument also involves imaginative construction on the part of the evaluator. The fact that considerable debate exists over how to fill in missing premises suggests that it may not be possible to formalize a method for doing so. The constructive dimension becomes even more salient in the case of finding unstated assumptions. As Scriven (1976) has demonstrated, finding the illuminating assumptions of an argument as opposed to the obvious unhelpful ones requires "a substantial slice of original thinking" (169). Context and background knowledge as well as informal logical principles are required in order to reconstruct an argument. 
The process of argument evaluation also displays a creative dimension. Most natural language arguments are not strictly deductive but rather contain types of reasoning which leave some play between the premises and conclusions. As Blair and Johnson (1987) point out, arguments may contain reasoning in which:

the conclusion follows, ceteris paribus, or on balance, or in some other qualified way which suggests a more tenuous relationship between premises and conclusions than would be the case with either deductive or inductive reasoning (43).

As a consequence, the procedure for the assessing of arguments cannot be formalized. There is room for differences of view with respect to the evaluation of particular arguments.

This indeterminacy can be seen in that aspect of argument evaluation dealing with the identification of fallacies and is apparent with respect to all three types of fallacies: fallacies of relevance, of sufficiency and of acceptability. There may, for example, be legitimate debate as to the relevance of certain considerations to an argument and a judgment regarding relevance may depend on what unstated assumptions are supposed. According to Johnson and Blair (1983, 39), "relevance is always a judgment call, and there is no reason to think that any algorithmic procedure will come along to change that." The situation is similar with respect to fallacies of sufficiency. Although there are principles that guide the assessment of sufficiency, there is no algorithm for determining how much evidence is sufficient. And again with respect to acceptability, Johnson and Blair (1983) tell us that judgments of acceptability are dialectical and must be determined with an imagined audience in mind and in light of purposes.

Evaluating arguments by analogy also requires a contribution on the part of the assessor. Determining the appropriateness of an analogy involves imagining the similarities and differences between the cases and may require considerable imaginative reconstruction and the supplying of context.

Inventing a counter-example to test the strength of an argument is clearly a creative act, as is the consideration of alternative arguments. As Scriven (1976, 36) so eloquently states:

The process of trying to think of alternative explanations of a set of facts ... is an entirely creative process. It is exactly the process which the great original scientist goes through in coming up with a novel theory. There are no precise rules to guide one in such a search, and it requires imagination nurtured by a rich and varied experience to generate the novel hypothesis here. So the very process of criticism necessarily involves the creative activity of generating new theories or hypotheses to explain phenomena that have seemed to other people to admit of only one explanation.

An aspect of argumentation which falls within the domain of informal logic but which seems to be ignored by Rorty's exclusion of argument from innovation is the construction of arguments. The activity of argumentation does not consist solely in interpreting and evaluating already existing arguments. It also consists in 
coming up with arguments. And coming up with new arguments is a creative activity, consisting in the recognition of problems or alternatives and the construction of a coherent chain of reasoning. Such construction must, however, conform to all the critical standards that guide evaluation. Moreover, the constructor must recognize any logical vulnerabilities in the argument. The constructor is, then, simultaneously a critic. The critic makes an imaginative contribution to the assessment in all the ways previously described and must be able to construct a cogent argument to support the critique. The critic is, then, simultaneously a constructor. Argument construction and critique are, thus, inseparable and intertwined aspects of the same process, the process of argumentation.

In considering the role of argument in conceptual change, it is important to focus on the whole process of argumentation and not just on the assessment of isolated arguments. Argumentation is a dialectical process that involves the construction as well as the evaluation of particular arguments but also, ultimately, of entire belief sets or views. In the process of argumentation, claims are proposed along with their justification, the claims and reasons are tested and challenged, they may be rejected or reformulated, alternative arguments may be proposed, these will be tested and perhaps reformulated, and in the end a view is arrived at which takes into account the strengths and weaknesses of the various arguments and synthesizes the strongest elements into a coherent whole. The view thus arrived at will be provisional as any particular instance of argumentation is but one piece of a larger process of belief formation and testing (Blair and Johnson 1987), one moment in an ongoing disciplinary and social conversation (Bailin 1992b).

\section{Inquiry}

What I am offering, then, is an alternative picture of how inquiry proceeds to the one suggested by Rorty. For Rorty, inquiry seems to be constituted by two distinct and separate kinds of activities. On the one hand there is the analytic, logical, bounded and conservative activity of argumentation or criticism, which works with existing concepts and allows for the manipulation of elements within frameworks that are static, singular and self-contained. On the other hand we have the speculative, creative, progressive activity of strong poetry, which transcends frameworks and creates new ideas, new visions, and new vocabularies unconstrained by the strictures of critical judgment and argumentation.

What 1 propose is a picture of inquiry as a single activity constituted by the dynamic interplay between generation and criticism. Engaging in our various traditions and practices of inquiry always and simultaneously involves both. In attempting to solve problems posed by the tradition, both the constraints of logic and the inventiveness of imagination come into play. And in some cases, our reasoning will lead us to question assumptions, break rules and put elements together in new ways-thus issuing in ideas that may display considerable novelty. 
This process of inquiry is instantiated in disciplines and traditions of inquiry that are open-ended, dynamic, plural, and overlapping. There are live questions, ongoing debates and areas of controversy within every discipline that furnish the arena for evolution and change (Bailin 1992a). Moreover, a central characteristic of rational inquiry is that "it aims to discover its own weaknesses and rectify what is at fault with its own procedures" (Lipman 1991, 121). Thus the critical procedures of the traditions provide for the possibility of the evolution of the tradition itself in light of new evidence and arguments, problems and limitations discovered in the course of inquiry, and criticisms from competing strands both within the tradition and outside it. There is no need to posit strong poetry to account for conceptual change. Argumentation, as instantiated in our traditions of inquiry, can achieve that goal.

I want to make clear that in making this argument, I am in no way denigrating the importance of poetry. I have great respect for, indeed passion for, poetry and think that the arts have a crucially important role to play in envisioning possible futures. They can, as Greene $(1995,112)$ tells us, move us into spaces where "we can create visions of other ways of being and ponder what it might signify to realize them". They can show us "in rich detail, as formal abstract argument cannot, what it is like to live a certain way" (Nussbaum 1990, 227-228). Thus they may conjure up evocative instantiations of those utopian visions, or equally powerful evocations of dystopian ones.

There are several points to be made here, however. First, poetic creations, like innovative works in other domains, are not discontinuous with the traditions out of which they develop. They have their roots in previous artistic traditions, methods, and problems; reveal influences from other artists; and employ critical analysis of aspects of society and culture. Insofar as such poetic visions are effective, insofar as they touch us and capture our imagination, considerable critical judgment (as well as imagination) would have gone into their creation. Second, this poetic activity does not obviate the necessity for critical evaluation of the ideas or visions thus created. I see poetry, then, as a complement to and not a substitute for argument.

\section{Conclusion}

It is time now to return to the question that prompted this investigation initially: is argument for conservatives? What I think this journey through views about the nature of innovation and the role of argument points to is that Rorty's idea is not a new one, and neither is it sparkling. Rather than forgetting where we once were as Rorty suggests, I think that it is crucially important to remember past traditions in order to participate in the critical dialogues that they embody and to further the conversation. 'Old routes of inference and feeling' can lead to new ones. Argument is not so flat after all. So perhaps we ought to throw open the doors of our studies, discard our visors and sleeve protectors, don our boots and take our rightful place in those conceptual fields, making our contribution to the growth of ideas. 


\section{Notes}

'This discussion of discontinuity is taken from Bailin (1992a).

${ }^{2}$ This discussion of generation as critical draws heavily on Bailin (1992a).

${ }^{3}$ For an elaboration of this argument regarding the generative dimension of criticism, see Bailin (1990).

\section{References}

Abrams, M.H. (1953). The Mirror and the Lamp. Oxford: Oxford University Press. Adams, James. (1986). Conceptual Blockbusting. Reading, MA: Addison-Wesley. Bailin, Sharon. (1992a). Achieving Extraordinary Ends: An Essay on Creativity. Norwood, NJ: Ablex.

Bailin, Sharon. (1992b). "Argumentation as Inquiry." In Frans H. van Eemeren, Rob Grootendorst, J. Anthony Blair and Charles A. Willard (eds.), Proceedings of the Second International Conference on Argumentation, 64-69. Amsterdam: International Society for the Study of Argumentation.

Bailin, Sharon. (1992c). "Culture, Democracy, and the University." Interchange 23, 1\&2: 63-69.

Bailin, Sharon. (1990). "Argument Criticism as Creative." In R. Trapp and J. Schuetz (eds.), Perspectives on Argumentation: Essays in Honor of Wayne Brockriede, 232240. Prospect Heights, IL: Waveland Press.

Barzun, Jacques. (2000). From Dawn to Decadence: 500 Years of Western Cultural Life. New York: Harper Collins.

Blackburn, Simon. (2001). "The Professor of Complacence," The New Republic, Aug., $39-42$.

Blair, J. Anthony and Ralph H. Johnson. (1987). "Argumentation as Dialectical." Argumentation 1, 1: 41-56.

Bono, Edward de. (1970). Lateral Thinking. London: Ward Lock Educational.

Brandom, Robert B. (ed.). (2000). Rorty and His Critics. London: Blackwell.

Brown, Harold. (1977). Perception, Theory and Commitment: The New Philosophy of Science. Chicago: Precedent Publishing Inc.

Feyerabend, Paul. (1975). Against Method. London: New Left Books.

Finocchiaro, Maurice. (1980). Galileo and the Art of Reasoning. Dordrecht: Reidel.

Giroux, Henri. (1991). Postmodernism, Feminism and Cultural Politics: Redrawing Educational Boundaries. Albany: SUNY Press.

Greene, Maxine. (1995). "Texts and Margins." In R. Neperud (ed.), Context, Content and Community. 111-127. New York: Teachers College Press.

Harding, Sandra. (1990). "Feminism, Science and the Anti-enlightenment Critiques." In L. Nicholson (ed.), Feminism/Postmodernism. 83-106. New York: Routledge.

Hattiangadi, Jagdish. (1980). "The Vanishing Context of Discovery." In T. Nickels (ed.), Scientific Discovery, Logic, and Rationality. 257-265. Dordrecht: Reidel.

Johnson, Ralph H. and J. Anthony Blair. (1983). Logical Self-Defense. Toronto: McGrawHill Ryerson. 
Lipman, Matthew. (1991). Thinking in Education. Cambridge: Cambridge University Press.

Miller, Arthur I. (1984). Imagery in Scientific Thought. Boston: Birkhauser.

Nickels, Thomas. (1980). "Introductory Essay: Scientific Discovery and the Future of Philosophy of Science." In T. Nickels (ed.), Scientific Discovery, Logic and Rationality. 1-59. Dordrecht: Reidel.

Nussbaum, Martha. (1990), Love's Knowledge: Essays on Philosophy and Literature. Oxford: Oxford University Press.

Oech, Roger von. (1986). A Kick In The Seat Of The Pants. New York: Harper Perennial. Oech, Roger von. (1983). A Whack on the Side of the Head. New York: Warner Books.

Perkins, David. (1981). The Mind's Best Work. Cambridge, MA: Harvard University Press.

Popper, Karl. (1959). The Logic of Scientific Discovery. New York: Harper Torchbooks.

Rorty, Richard. (1991). Objectivity, Relativism and Truth. Cambridge: Cambridge University Press.

Rorty, Richard. (1989). Contingency, Irony, and Solidarity Cambridge: Cambridge University Press.

Schaffner, Kenneth F. (1980). "Discovery in the Biomedical Sciences: Logic or Irrational Intuition?" In T. Nickles (ed.), Scientific Discovery: Case Studies. 171-205. Dordrecht: Reidel.

Scriven, Michael. (1976). Reasoning. New York: McGraw-Hill.

Taylor, Charles. (1989). Sources of the Self: The Making of the Modern Identity. Cambridge, MA: Harvard University Press.

Toulmin, Stephen. (1972). Human Understanding. Princeton: Princeton University Press. Weisberg, Robert. (1993). Creativity: Beyond the Myth of Genius. New York: W.H. Freeman.

Sharon Bailin Faculty of Education Simon Fraser University Burnaby, BC V5A IS6 Canada 